\title{
Physico-Chemical Study of Herbal Ghee Prepared with Ethanolic Extract of Asparagus racemosus (Shatavari) and Withania somnifera (Ashwagandha)
}

\author{
A.R. Deshmukh*, R.J. Desale, Y.G. Fulpagare and S.M. Khupse \\ Department of Animal Husbandry and Dairy Science, Mahatma Phule Krishi Vidyapeeth, \\ Rahuri-413 722, Dist. Ahmednagar, Maharashtra, India \\ *Corresponding author
}

\begin{tabular}{|c|}
\hline $\mathbf{K}$ \\
\hline $\begin{array}{l}\text { Asparagus racemosus, } \\
\text { Withania somnifera, } \\
\text { Refractive index, Specific } \\
\text { gravity, Melting point, } \\
\text { Moisture content, Free fatty } \\
\text { acid, Ghee, Peroxide value, } \\
\text { Phtosterol content, Storage } \\
\text { stability }\end{array}$ \\
\hline Article Info \\
\hline $\begin{array}{l}\text { Accepted: } \\
\text { 04 July } 2018 \\
\text { Available Online: } \\
10 \text { August } 2018\end{array}$ \\
\hline
\end{tabular}

\section{Introduction}

Milk is universally accepted as nearly complete food for neonates in animals as well as human beings of all ages. It contains rich source of almost all essential nutrients in proper proportion for growth and development of human being.

Ghee is the most widely used milk product in the Indian sub-continent and is considered as
The following analysis entitled "Physico-chemical study of herbal ghee prepared with ethanolic extract of Asparagus racemosus (Shatavari) and Withania somnifera (Ashwagandha)" was conducted with the objective to enhance the quality and anti-oxidant ability of ghee using physic-chemical tests. With this hypothesis, is planned with objective to study the physico-chemical and organoleptic properties of herb extracts ghee. Treatment details: $\mathrm{T}_{0}$-Control; $\mathrm{T}_{1}$-Ashwagandha Extract: $0.50 \%$; $\mathrm{T}_{2}$-Shatavari Extract: $0.50 \% ; \mathrm{T}_{3}$ Ashwagandha+ Shatavari Extract: $0.20+0.20 \% ; \mathrm{T}_{4}$ - Synthetic antioxidants BHA (Butylatedhydroxy anisole): $0.02 \%$. By these studies it was concluded that herbal ghee was effective in high range of refractive index (42.08) in Shatavari ghee (T2, 0.5\%). Specific gravity ranged from 0.89 to 0.91 with an average of 0.90 . The lower range of melting point (32.63) and moisture content $(0.14 \%)$ was observed in Shatavari ghee (T2, $0.5 \%)$. The free fatty acid (\% oleic acid content) in herb extract ghee samples conformed to the standards prescribed by AGMARK for ghee in India. Phytosterol content $(0.15)$ was highest in ghee prepared in T4 (BHA, 0.02\%). The iodine value content was slightly increased (35.48) in herb extract ghee. After all these studies were suggested that ethanolic extract of Asparagus racemosus and Withania somnifera could be used as an antioxidant and enhancing the phytosterol content in ghee. 
other fats mainly because of the presence of characteristic short chain fatty acids, carrier of four fat soluble vitamins viz., A, D, E, K and essential fatty acids such as linolenic acid and arachidonic acid.

In recent decades, there has been great interest in screening essential oils and various plant extracts for natural antioxidants. In order to prolong the storage of foods, several synthetic antioxidants such as butylatedhydroxy toluene (BHT) and butylatedhydroxy anisole (BHA) are used currently, but these substances are in appropriate for chronic human consumption, as recent publications have mentioned their toxic properties for human health and the environment (Itio et al., 1986). Hence, the development of alternative antioxidants of natural origin has attracted considerable attention and is thought to be a desirable development (Jia et al., 2007).

Asparagus racemosus (Shatavari) and Withania somnifera (Ashwagandha) belonging to family Asparagaceae and Solanaceae, respectively have an esteemed place in Ayurveda. The active components of Puerariatuberosa are puerarin, daidzein, genistein and daidzin (Pandey et al., 2007); Asparagus racemosus are steroidal glycosides, saponins, polyphenols, flavonoids, galactose and vitamins (Thomson, 2002) and Withania somnifera are steroidal lactones (withanolides), sitoindosides and steroidal alkaloids.

All these herbs have been reported to possess several therapeutic properties. They are also known to possess antioxidant activity in vivo condition (Verma et al., 2009). Asparagus racemosus is reported to have immunostimulant, antihepatotoxic and antioxytocic activities (Goyal et al., 2003), and antioxidant and anti-diarrheal activities in laboratory animals (Bhatnagar et al., 2005). Withania somnifera (Ashwagandha) is one of the major herbal components of geriatric tonics, this plant is also claimed to have potent aphrodisiac, rejuvenative and life prolonging properties (Sharma, 1997).

\section{Shatawari (Asparagus racemosus)}

Asparagus racemosus (family Liliaceae), is commonly called Shatavari, Satawar or Satmuli in Hindi; Satavari in Sanskrit. It is considered both a general tonic and a female reproductive tonic. The major active constituents are steroidal saponins.

Root of Asparagus racemosus has been referred as bittersweet, emollient, cooling, nervine tonic, constipating, galactogogue, aphrodisiac, diuretic, rejuvenating, carminative, stomachic, antiseptic (Chopra et al., 1994) and as tonic. Beneficial effects of root of Asparagus are suggested in nervous disorders, dyspepsia, diarrhoea, dysentery, tumors, inflammations, hyperdipsia, neuropathy, hepatopathy, cough, bronchitis, hyperacidity and certain infectious diseases (Sharma et al., 2000). The fresh root juice mixed with honey is given to relieve dyspepsia.

\section{Ashwagandha (Withania somnifera)}

Withania somnifera, also known as Ashwagandha, Indian ginseng and winter cherry, has been an important herb in the Ayurvedic and indigenous medical systems for over 3000 years. Ashwagandha in Sanskrit means "horse's smell", probably originating from the odour of its root which resembles that of sweaty horse (Puri, 2003). The species name somnifera means "sleep-bearing" in Latin, indicating it was considered a sedative, but it has been also used for sexual vitality and as an adaptogen.

Ashwagandha roots contain alkaloids, starch, reducing sugar, glycosides, dulcitol, withaniol 
acid and a neutral compound. Wide variation $(0.13-0.31 \%)$ is observed in alkaloid content. Majumdar (1955) isolated 8 amorphous bases such as withanine, somniferine, somniferinine, somnine, withananine, withananinine, pseudowithanine and withasomnine. Withania roots are astringent, bitter, acrid, somniferous, thermogenic, stimulant, aphrodisiac, diuretic and tonic. Leaf is antibiotic, antitumorous, antihepatotoxic and antiinflammatory. Seed is milk coagulating, hypnotic and diuretic.

\section{Materials and Methods}

\section{Cream}

The fresh clean cream was collected from Research Cum Development Project on Cattle, Department of Animal Husbandry and Dairy Science, M.P.K.V., Rahuri, Dist. Ahmednagar. The cream was collected immediately after morning milking.

Ashwagandha (Withania somnifera) and Shatavari (Asparagus racemosus)

Ashwagandha and Shatavari powder as a source of natural herb were purchased from All India Coordinated Project on Medicinal and Aromatic Plants and Beetle Vine Research, MPKV, Rahuri, Dist. Ahmednagar.

\section{Synthetic antioxidant}

Synthetic antioxidant required as antioxidant agent was purchased from $\mathrm{M} / \mathrm{s}$. Dodal Enterprises, Shrihari Plaza, New Gulmandi Road, Aurangabad. 431001.

\section{Addition of antioxidants}

The ethanolic extract of Ashwagandha (Withania somnifera) and Shatavari (Asparagus racemosus) added at the rate of 0.5 per cent into the freshly prepared ghee, while synthetic antioxidant such as BHA was added at the rate of 0.02 per cent into the ghee.

\section{Physical property analysis}

\section{Butyro- refractometer reading (BR)}

It was estimated by Brix hand refractometer.

\section{Specific gravity}

It was determined using pycnometer method described in I.S.I. Hand book of Food analysis (Part XIII) 1984, page 72).

\section{Melting point by using digital calorimeter}

The melting point of a solid can be easily and accurately determined with small amounts of material, it is the physical property that has most often been used for the identification and characterization of solids.

\section{Moisture content}

It was estimated as per procedure given by I.S 3508 - 1966 Methods of sampling and test for Ghee.

\section{Chemical analysis of ghee}

\section{Free Fatty Acid (FFA)}

Determined by standard method as described in Indian standard (IS: 3508-1966) in terms of $\%$ oleic acid.

\section{Phytosterol content}

Determined by the direct colorimetric method as described by (Sabir et al., 2003).

\section{Iodine value}

Determined by the Wij's method.

\section{Statistical analysis}

The data generated during the course of this investigation was analyzed with the help of 
Completely Randomized Design (CRD) for pre-experimental trials and final experimental trials (Panse and Sukhatme, 1985).

\section{Results and Discussion}

\section{Refractive index}

BR reading decreases as the adulteration increases. The Butyro-refractometer (BR) reading at $40 \pm 1^{\circ} \mathrm{C}$ for fresh control cow ghee (without added antioxidant) was 41.93, It shows high range in Shatavari ghee 42.08 (Fig. 1 and 2).

The refractive index of milk fat generally, ranges between 1.4538 and 1.4578. Lea (1939) reported that increase in BR with the increase in peroxide value on storage. Achaya (1949) on the other hand observed an erratic behavior of BR and reported that amongst all the fat constants the BR was least affected on storage. A slight but consistent increase in BR of all ghee samples was observed on storage (Reddy, 1982).

\section{Specific gravity}

The average specific gravity for cow ghee is 0.8988 . The minor differences in specific gravity of control cow ghee and herb extract added ghee could be attributed to differences in fatty acids composition, the specific gravity of fresh control cow ghee (without added antioxidant) was 0.89 for Ashwagandha $(0.5 \%)$, for Shatavari $(0.5 \%)$ and Ashwagandha+ Shatavari $(0.20+0.20 \%)$ ghee specific gravity was 0.90 and for Synthetic antioxidants BHA is of 0.89 , respectively (Figure 3).

\section{Melting point-}

The average melting point of pure cow ghee is 33.7 to $35.8^{0} \mathrm{C}$, The Figure 4 shows that the melting point high range in $\mathrm{T}_{3}, 33.20$ (Ashwagandha+ Shatavari $0.20+0.20 \%$ ) cow ghee and lower in $T_{2}, 32.63$ (Shatawari) ghee. Melting point (slip point) of various oils and fats covers a wide range and this property has been employed for checking the adulteration of milk fat. Body fats $\left(36-51.3^{\circ} \mathrm{C}\right)$ and vanaspati $\left(37.8-38^{\circ} \mathrm{C}\right)$ have slightly higher melting point (Winton and Winton, 1999) while vegetable oils $\left(20-30^{\circ} \mathrm{C}\right)$ have slightly lower melting point than milk fat $\left(28-41^{\circ} \mathrm{C}\right)$ as reviewed by Arun et al., (2002).

\section{Moisture content}

The shelf stability of ghee, one of its major quality characteristics, is mainly dependent on the low moisture content. The standard specifies ghee to have 96 per cent minimum milk fat, 0.3 per cent maximum moisture. The moisture content of control ghee sample was0.22 per cent and Ashwagandha, Shatavari, Ashwagandha + Shatavari and Synthetic antioxidants BHA cow ghee was 0.15 per cent, 0.14 percent, 0.15 per cent, and 0.16 per cent, respectively. The lowest moisture content was observed in $\mathrm{T}_{2}$ i.e. Shatavarighe (Figure 5). Initial moisture content of the milk fat affects the shelf life. Iskander et al., (1985) reported that better oxidative stability of butter oil than ghee samples which might be due to low initial moisture content in butter oil.

\section{Chemical constituent of ghee prepared with herbs extract and BHA}

\section{Free fatty acid (\% oleic acid) content in ghee}

The Free fatty acid (\% oleic acid) content for fresh control cow ghee (without added antioxidant) was of 0.23 per cent, while the effect of herb extract incorporation on development of FFA showed almost similar FFA content 0.23 per cent and synthetic antioxidant (BHA) content low FFA 0.20 per cent (Fig. 6 and 7). 
Fig.1 Physical properties of ghee prepared with herbs extract and BHA at $37 \pm 1{ }^{0} \mathrm{C}$

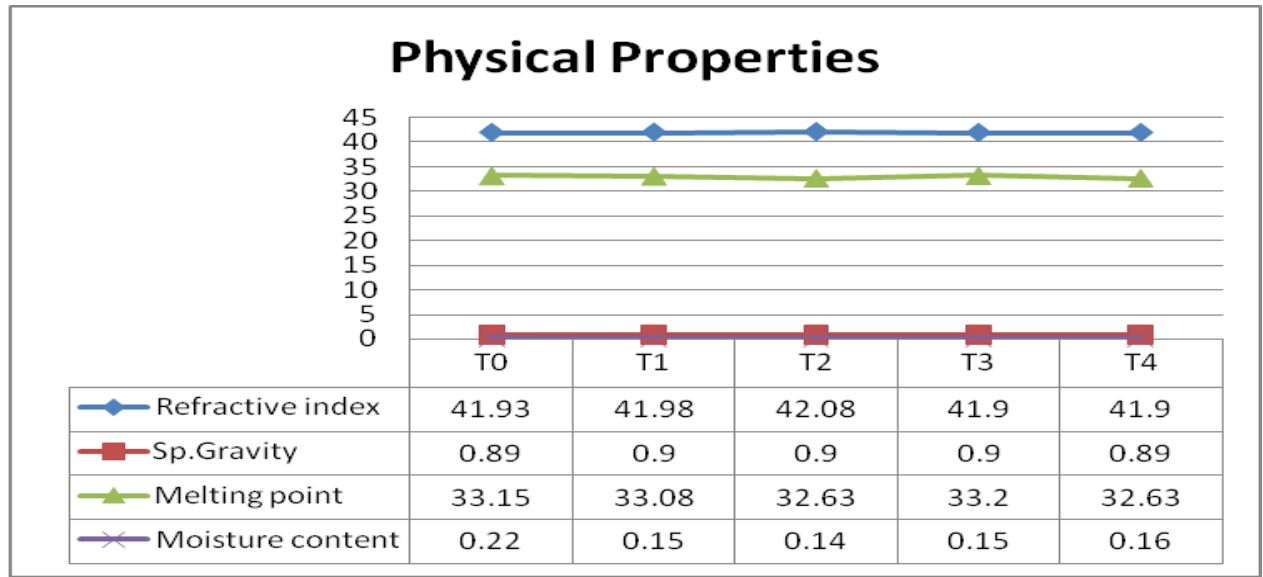

Fig.2 Refractive Index of ghee prepared with herbs extract and BHA

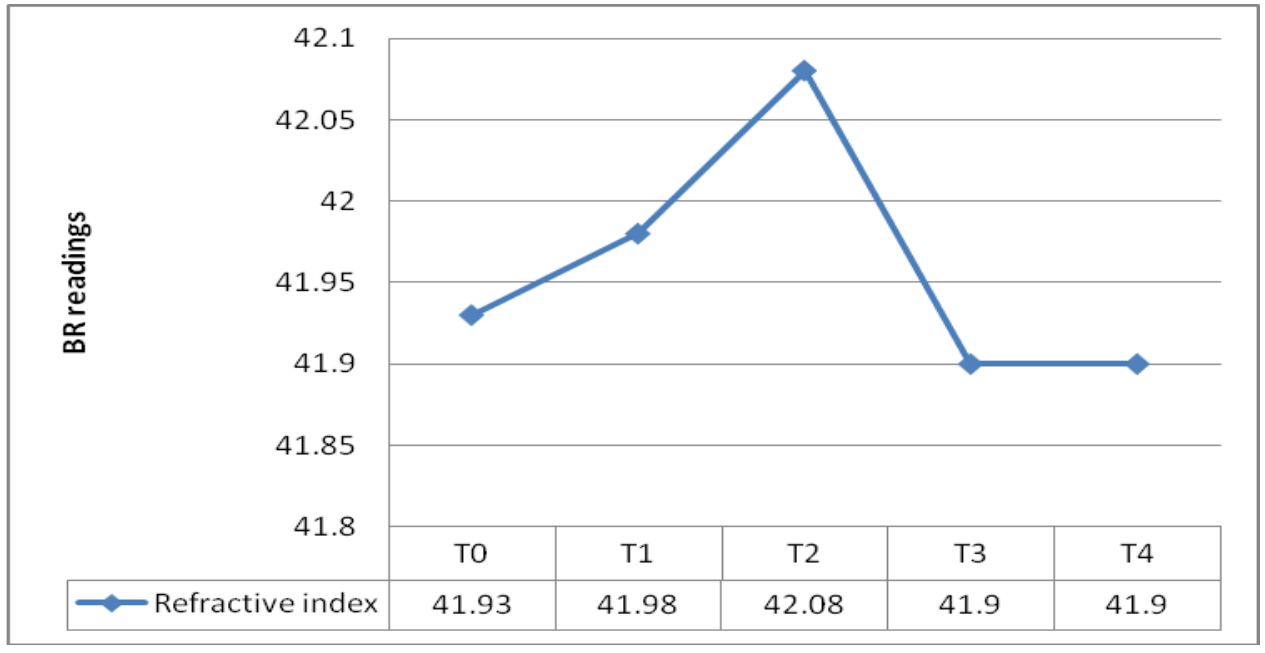

Fig.3 Specific gravity of ghee prepared with herbs extract and BHA

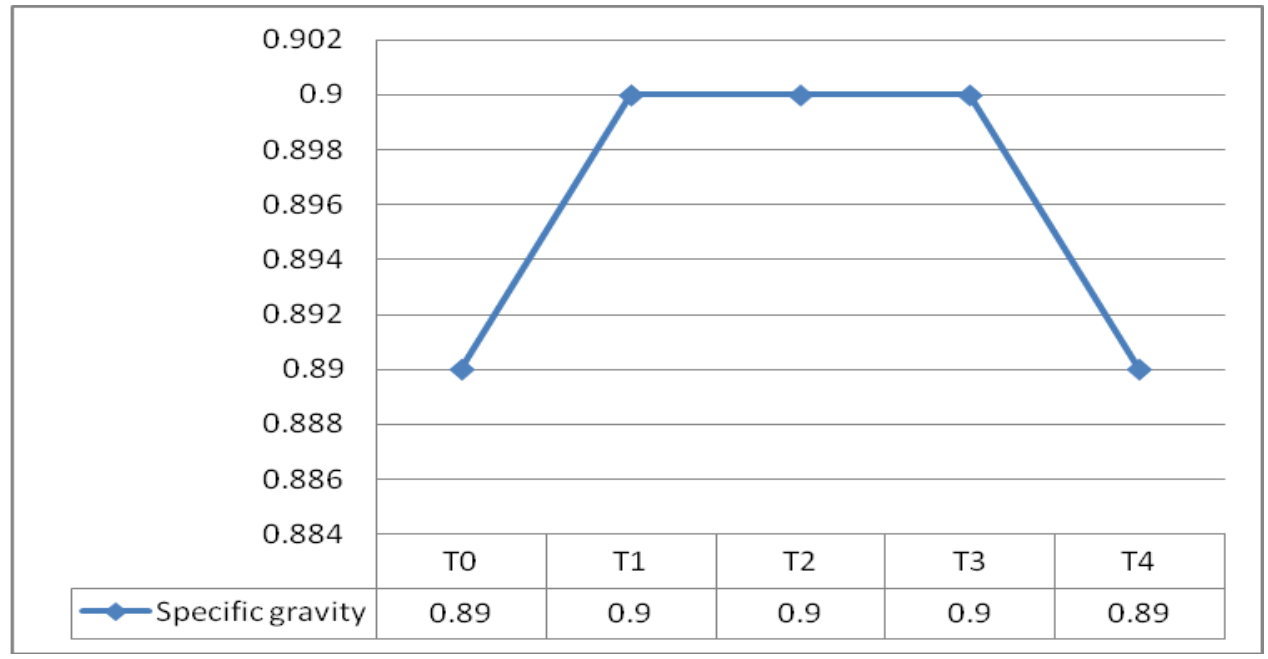


Fig.4 Melting point of ghee prepared with herb extract and BHA

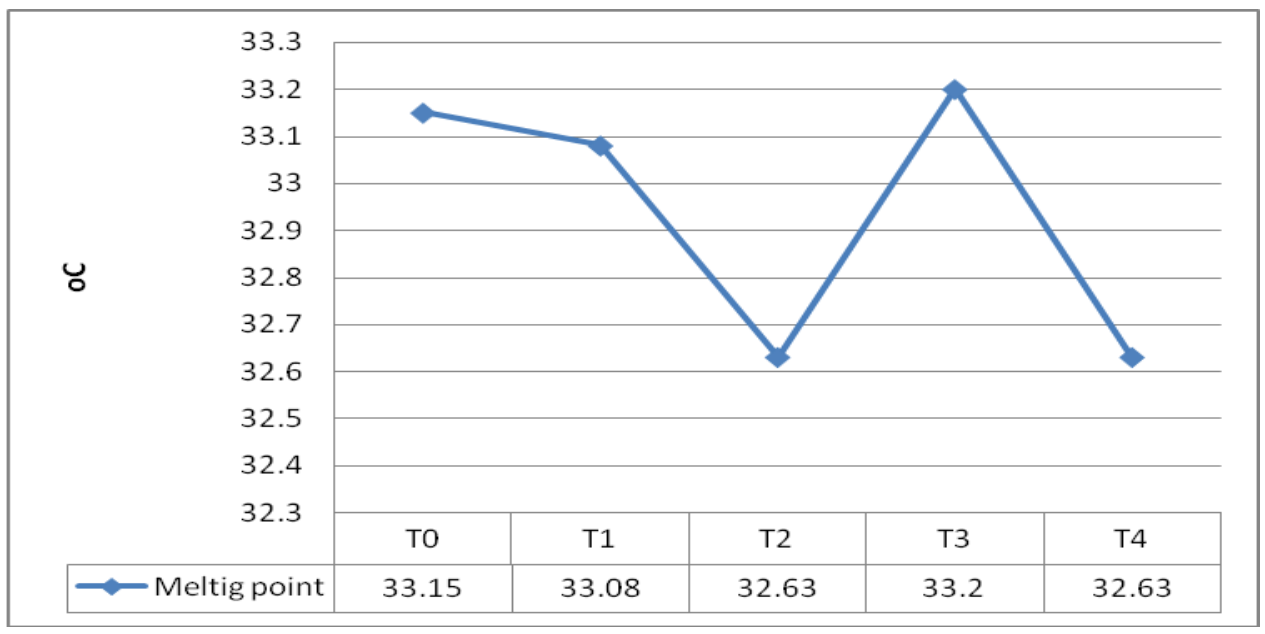

Fig.5 Moisture content of ghee prepared with herbs extract and BHA

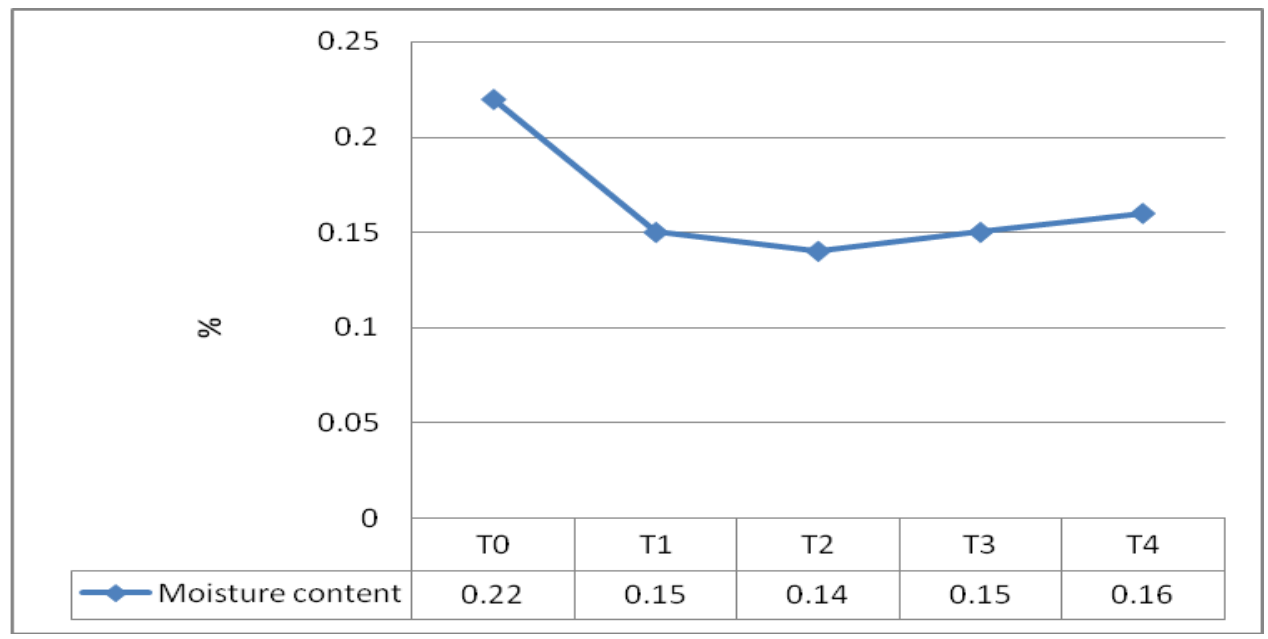

Fig.6 Chemical properties of ghee prepared with herbs extract and BHA at $37 \pm 1{ }^{0} \mathrm{C}$

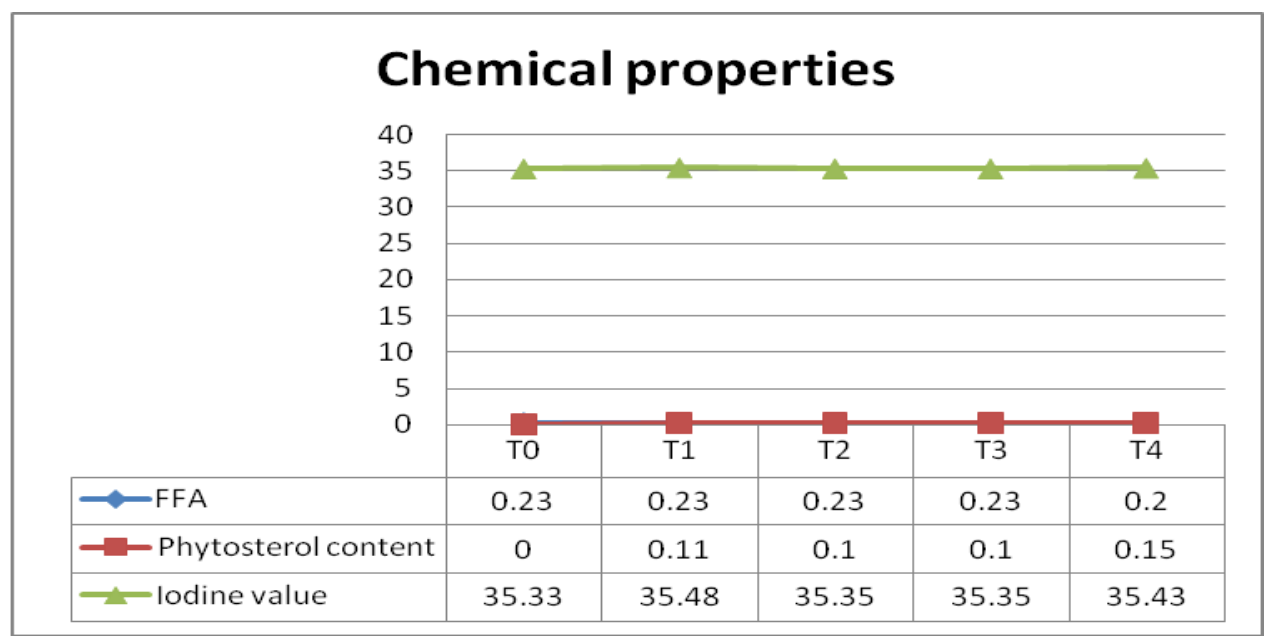


Fig.7 Free fatty acid content of ghee prepared with of herbs extract and synthetic antioxidants

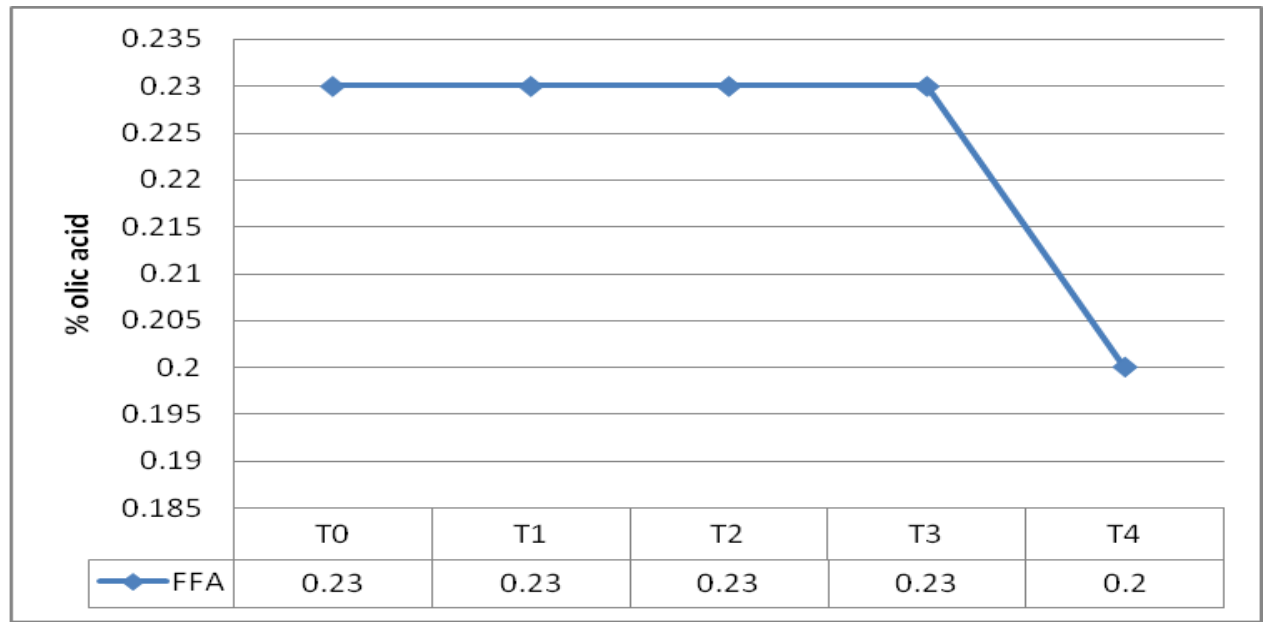

Fig.8 Phytosterol content of ghee prepared with herbs extract and BHA

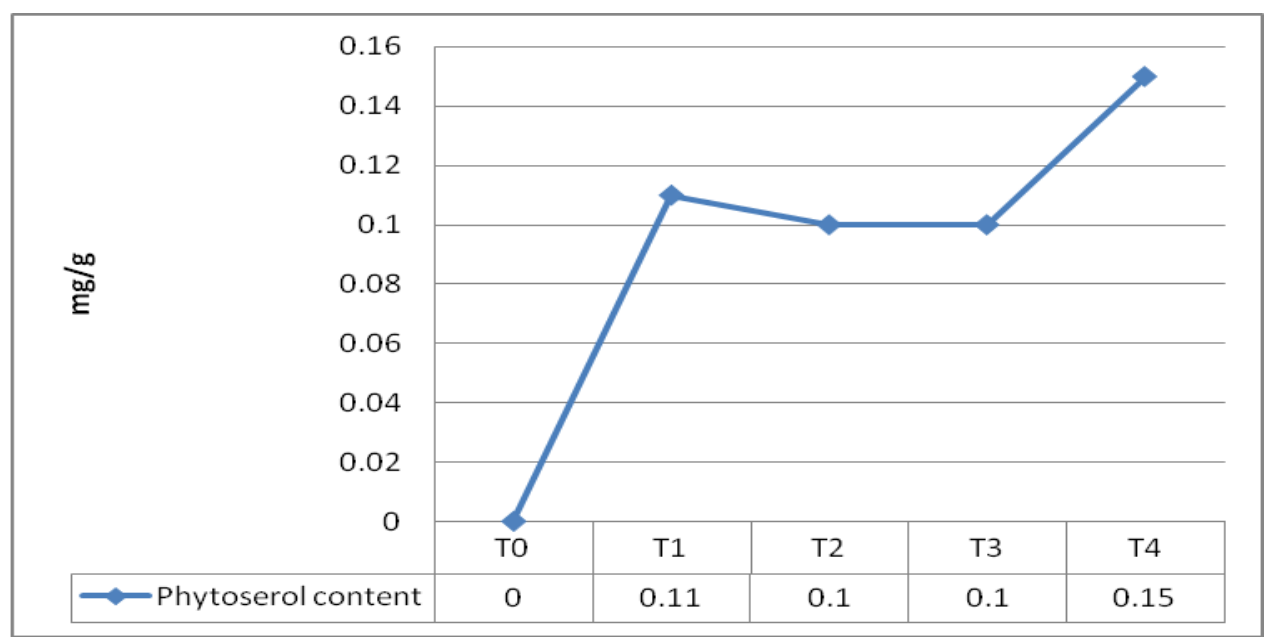

Fig.9 Iodine content of ghee prepared with herbs extract and BHA

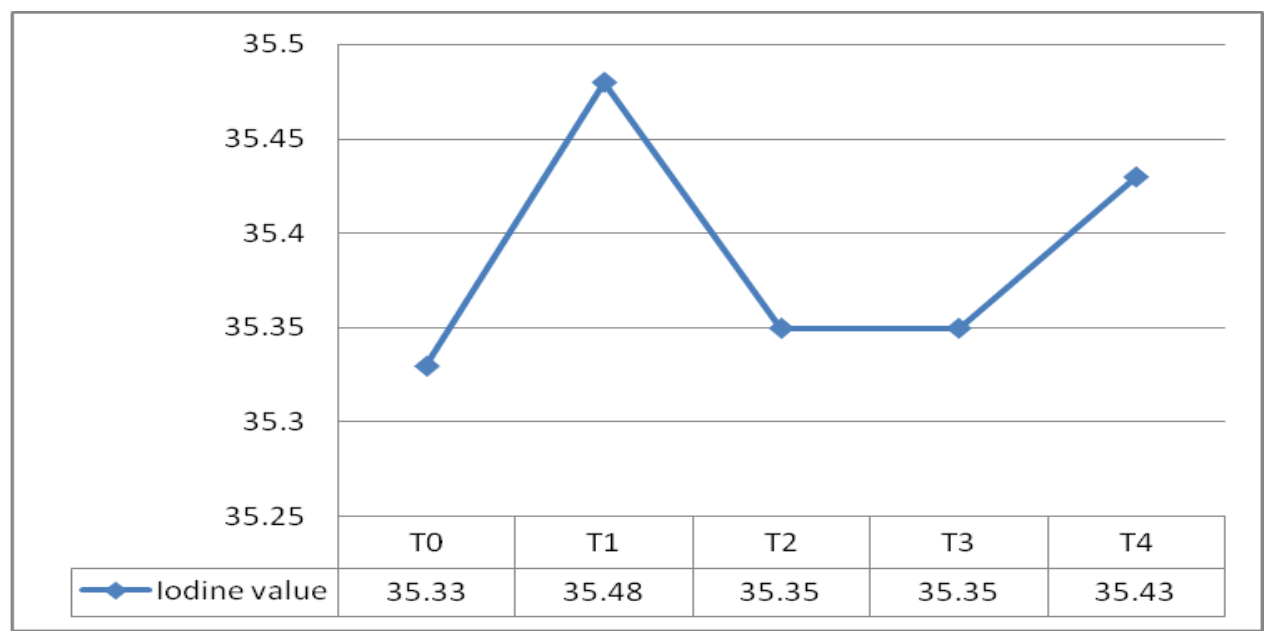


All the treatments of ghee samples conformed to the standards prescribed by AGMARK for ghee in India related to FFA.

\section{Phytosterol content}

It was observed that there was a significant difference $(\mathrm{p}<0.05)$ in the phytosterol content $(\mathrm{mg} / \mathrm{g})$ of the herbal ghee prepared from three different types of extracts. The retention of phytosterol was highest in case of ghee prepared from Ashwagandha extract powder (0.11) followed by ghee prepared from Shatawari extract and combination of thereof (0.10). The phytosterol content $(\mathrm{mg} / \mathrm{g})$ of synthetic antioxidant (BHA) is higher than herb extract (0.15). Based on the above results it could be concluded that the phytosterol content was highest in ghee prepared in treatment $\mathrm{T}_{4}$ (BHA) over rest of the other treatments, followed by treatment $\mathrm{T}_{1}$ (Ashwagandha) respectively (Fig. 8).

\section{Changes in iodine value}

The Iodine value for fresh control cow ghee (without added antioxidant) was of 35.33, while for Ashwagandha (Withania somnifera), Shatavari (Asparagus racemosus), combination thereof and BHA ghee (with added antioxidant) were $35.48,35.35,35.35$ and 35.43 , respectively. The study indicated that there was a small (NS) increase in Iodine value in ghee added with herb extract than control ghee (Fig. 9).

The physical analysis of ghee prepared with best treatment shows high range of refractive index (42.08) in Shatavari ghee $\left(\mathrm{T}_{2}\right)$. Specific gravity ranged from 0.89 to 0.91 with an average of 0.90 . The lower range of melting point (32.63) and moisture content $(0.14 \%)$ was observed in Shatavarighee.

The free fatty acid (\% oleic acid content) in all the experimental treatment samples conformed to the standards prescribed by AGMARK for ghee in India.

Phytosterol content (0.15) was highest in ghee prepared in $\mathrm{T}_{4}$ (BHA). The iodine value content was slightly increased (35.48) in herb extract ghee.

\section{References}

Achaya, K.T. 1997. Ghee, vanaspati and special fats in India. In Lipid Technologies and Applications, F.D. Gunstone and F.B. Padley (eds), Marcel Dekker Inc., New York. 369-390.

Arun Kumar, Lal, D., Seth, R. and Sharma, R. 2002. Recent trends in detection of adulteration in milk fat- A Review. Indian J. Dairy Sci. 55(6): 319-330.

Bhatnagar, M., Sisodiya, S. S. and Bhatnagar, R. 2005. Antiulcer and antioxidant activity of Asparagus racemosus WILLD and Withania somnifera DUNAL in rats. Annals of the New York Academy of Sciences. 1056: 261-270.

Chopra, R. N., Chopra, I. C., Handa, K. C. and Kapur, L. D. 1994. Indigenous drugs of India. Culcutta: Academic Publishers: 496.

Goyal, R. K., Singh, J. and Lal, H. 2003. Asparagus racemosus - an update. Indian Journal of Medical Research. 57: 408-14.

Hazra and Parmar. 2014. Natural Antioxidant use in ghee-A mini review. Journal of Food Research and Technology. 2 (3): 101-105.

Itio, N., Masaohiroses, Hojifukushimhair, Oyuktisuda, Masaetatematsanud and Makotoasamoto. 1986. Modifying effects of antioxidants on chemical carcinogenesis. Toxicologic pathology. 14(3): 315-323.

Jia, Z., Taofeia, Guo Lingb, Tao Guanjuna and Ding Xiaolina. 2007. Antioxidant properties of extract from juemingzi 
(Cassia tora L.) evaluated in vitro. LWT 40: 1072-7077.

Majumdar, D. N. 1955. Withania somnifera Dunal II Alkaloid constituents and their chemical characterisation. Indian Journal of Pharmacology. 17: 158-160.

PandeyNidhi, Chaurasia, J.K., Tiwari O.P., Yamini, B. and Tripathi. 2007. Antioxidant properties of different fractions of tubers from Puerariatuberosa Linn. Food Chemistry. 105: 219-222.

Puri, H. S. 2003. RASAYAN: Ayurvedic Herbs of Rejuvenation and Longevity. London: Taylor and Francis.

Sharma, P. C., Yelne, M.B. and Dennis, T.J. 2000. Database on medicinal plants used in ayurveda, volume I. Central council for research in ayurveda and siddha. Yugantar Prakashan (P.) Ltd., New Delhi, pp. 418-430.

Sharma, P. V. 1997. Dravyagunavigyan, chowkambhasanskritsansthan.

Thomson, M., Al-Qattan, K.K., Al-Sawan, S.M., Alnaqeeb, M.A., Khan, I. and Ali, M. 2002.The use of ginger (Zingiber officinale Rosc.) as a potential antiinflammatory and antithrombotic agent. Prostaglandins Leukot. Essent. Fatty Acid.67: 475-478

Verma S.K. and Jain V. Vyas A. 2009. Fibriolysis enhancement by Purerariya Tuberosa (Indian Kundu) in patients with coronary artery disease: A placebo controlled study. Journal of Cell and Tissue Research. 9(1): 1649-1654.

\section{How to cite this article:}

Deshmukh, A.R., R.J. Desale, Y.G. Fulpagare and Khupse, S.M. 2018. Physico-Chemical Study of Herbal Ghee Prepared with Ethanolic Extract of Asparagus racemosus (Shatavari) and Withania somnifera (Ashwagandha). Int.J.Curr.Microbiol.App.Sci. 7(08): 257-265. doi: https://doi.org/10.20546/ijcmas.2018.708.031 